\title{
24-hour tape recordings of ECG and respiration in the newborn infant with findings related to sudden death and unexplained brain damage in infancy
}

\author{
D P SOUTHALL, JEAN RICHARDS, D J BROWN, P G B JOHNSTON, M DE SWIET, \\ AND E A SHINEBOURNE
}

Department of Paediatrics, Brompton Hospital, and Cardiothoracic Institute, London

SUMMARY A system for simultaneous 24-hour tape recording of ECG and respiration has been developed and used in the study of 4 groups of newborn infants. In 50 randomly selected, healthy term infants, the mean lowest heart rate ( $>9$ beats' duration; was $88 \pm 13.14(28 \%)$ infants had junctional escape rhythms, 5 had supraventricular, and 2 ventricular premature beats. 34 (68\%) subjects had apnoeic episodes $\geqslant 10$ seconds' duration; the 95 th centile for maximum duration of apnoea was 18 seconds, the longest episode being 28 seconds. Episodes of bradycardia $<100 /$ minute were associated with 50 of a total of 288 episodes of apnoea of 10-14 seconds, with all 4 episodes of 15-19 seconds, and with both episodes $\geqslant 20$ seconds.

In 100 randomly selected, healthy, preterm or low birthweight infants studied within 5 days of their discharge from hospital, the mean lowest heart rate was $91 \pm 18.18$ had junctional, one idioventricular, and 3 both junctional and idioventricular escape rhythms. Two had supraventricular and 6 had ventricular premature beats. 66 subjects had apnoeic episodes $\geqslant 10$ seconds' duration; the 95th centile for maximum duration of apnoea was 20 seconds, the longest episode being 52 seconds. Episodes of bradycardia $<100 / \mathrm{min}$ were associated with 84 of a total of 608 episodes of apnoea $10-14$ seconds' duration, with 21 of 37 episodes of $15-19$ seconds, and with 15 of $15 \geqslant 20$ seconds. One preterm infant with a maximum apnoeic episode of 52 seconds had an associated bradycardia of $27 / \mathrm{min}$.

Three of 5 'near-miss' cot death infants and one preterm infant with a family history of cot death studied immediately before discharge showed prolonged apnoea $>40$ seconds, or extreme bradycardia $<50 /$ min, or both.

Finally, 11 infants with arrhythmias on a standard ECG were studied. Of these, 6 with premature beats and 3 of 5 with episodes of bradycardia did not exhibit apnoea during arrhythmias. Two of the 5 babies with bradycardia however, demonstrated associated apnoea of 10-14 seconds.

There may be a relationship between latent episodes of prolonged apnoea and bradycardia and hypoxaemic brain damage or sudden infant death.

Standard and 24-hour ECGs have shown that disturbances of heart rate and rhythm are common findings in the neonate. ${ }^{1-3}$ Apnoea in preterm infants is associated with episodes of bradycardia ${ }^{4-5}$

Cardiothoracic Institute

D P SOUTHALL, lecturer in paediatrics

JEAN RICHARDS, research assistant

M DE SWIET, senior lecturer

E A SHINEBOURNE, senior lecturer

Brompton Hospital

D J BROWN, mathematician

Dorset County Hospital

P G B JOHNSTON, consultant paediatrician and therefore, to investigate the relationship between disturbances of heart rate and rhythm and apnoea, we developed a combined 24-hour ECG and respiratory tape recording and analysis system. This equipment was used to study four groups of newborn infants.

Many preterm infants during the first days or weeks of life have prolonged apnoea. ${ }^{46}$ Prolonged apnoea has been suggested as a cause of sudden infant death syndrome (SIDS), ${ }^{7-8}$ and preterm infants have a higher incidence of SIDS..$^{9-11}$ This higher incidence in preterm infants may be due to a 
continuation, after discharge from hospital, of dangerous episodes of prolonged apnoea unnoticed by clinical observation. We therefore studied a group of 100 preterm infants when apparently well and about to leave hospital. As a control series we investigated 50 healthy term infants.

Previous studies have shown that some infants with 'near-miss' cot death episodes have prolonged apnoea, and 5 such infants were therefore studied. In addition, siblings of SIDS victims have been reported to be at excess risk of SIDS $^{9}$ and one such infant, who was also preterm, was studied before discharge from hospital.

Finally, 11 infants with cardiac arrhythmias on a standard ECG were investigated to determine whether changes in ECG pattern were associated with changes in respiration.

\section{Patients and methods}

50 control infants were randomly selected from the maternity units of Dorchester and Weymouth hospitals. All were term ( $>37$ weeks) in gestation and $>2.5 \mathrm{~kg}$ at birth. Their ages ranged from 1 to 15 days (mean 4 ).

A random group of 100 infants with birthweights $<2.5 \mathrm{~kg}$ or gestations $<37$ weeks, or both, were studied in the special care units of 9 hospitals within 5 days of their discharge home (Dorchester, Exeter, Queen Charlotte's, University College, Hillingdon, Kingston, Leicester, Hammersmith, and Brighton Hospitals). There were 51 boys and 49 girls; their ages ranged from 2 to 104 days, mean 26. Birthweights ranged from 840 to $2950 \mathrm{~g}$ (mean 1941) and gestation from 27 to 40 weeks (mean 34). 68 were preterm, 9 were small-for-dates, and 23 were both. 11 infants were one of twins. Postconceptional maturity at the time of recording varied from 36 to 47 weeks.

Five infants who had recently presented with 'near-miss' cot death episodes were studied by a single 24-hour recording after other investigations had failed to show abnormalities. These infants presented with attacks of pallor, cyanosis, and collapse. They recovered either spontaneously or after resuscitation by their parents. An additional infant was studied because his 2 previous siblings had died from SIDS. He was preterm (birthweight $1.50 \mathrm{~kg}$, gestation 30 weeks) and was investigated immediately before discharge home at age 78 days.

Finally, 11 infants with arrhythmias detected by a screening ECG performed routinely on all neonates in the Dorchester and Weymouth Maternity Hospitals were studied within the first 10 days of life.

\section{Recording technique}

24-hour ECG recordings were obtained using 2 electrodes positioned over the heart. A simultaneous respiration signal, provided by a separate impedance unit powered by a rechargeable battery, was obtained from two electrodes placed approximately $10 \mathrm{~cm}$ apart on the opposite side of the chest wall from the ECG electrodes (Fig. 1). Changes in electrical resistance brought about by change in the dimensions of the chest were received by the impedance unit and transferred to a second channel of a Medilog recorder (Oxford Medical Systems). ECG and respiration signals were checked during the recording by output leads to a test meter (Oxford Medical Systems). Infants were not disturbed by the electrodes and mothers were able, and encouraged, to handle and feed their babies in the usual way while recordings were being made either in the maternity nurseries or in the discharge section of the special care unit. All infants were in standard cots at the time of recordings.

Four factors influenced the quality of the respiratory recordings.

(1) Magnetic interference, which was avoided by bulk erasure of all cassettes before the 24-hour recording.

(2) Oxide coating of the tape head, which was prevented by the use of high quality cassettes and by cleaning the tape head and capstan with industrial spirit after every 3 recordings.

(3) The rechargeable lead acid batteries were unreliable in retaining charge. Each battery was tested for charge level before use.

(4) Excessive gain on the respiration pre-amplifier in the Medilog recorder, which gave rise to a characteristic artefact pattern (Fig. 2) and was corrected by appropriate adjustment.

The Medilog recorder and analyser incorporated a Synclock mechanism which ensured that by providing and processing a constant reference time signal, possible variations in tape speed did] not produce artefactual recordings which could be interpreted as rhythm, rate, or respiration disorders.

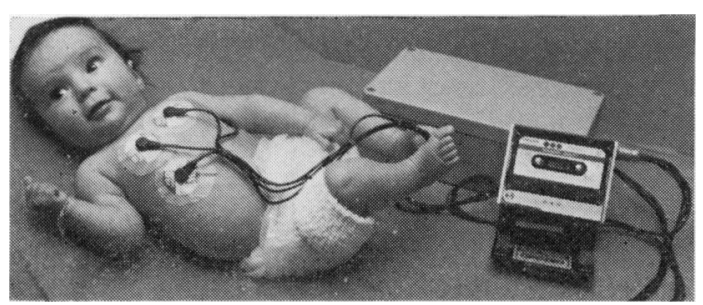

Fig. 1 The infant is attached to portable 24-hour ECG and respiration recorder by 4 pregelled electrodes. Two electrodes over the heart record the ECG, and the two over the opposite side of the chest provide and record the impedance signal. 

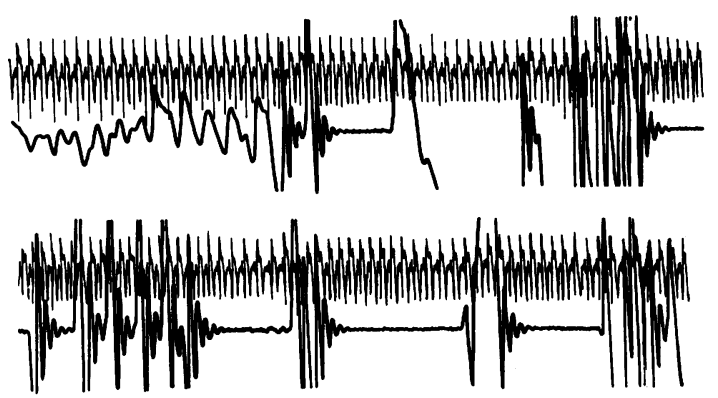

Fig. 2 24-hour ECG and respiration recording showing the ECG trace above a simultaneous respiration signal. Respiration trace shows a normal volume signal followed by a pattern characteristic of saturation of the preamplifier. The straight lines are artefacts and represent deep breaths not apnoea.

24-hour ECG and respiration analysis. The tapes were analysed using a system programmed to detect both apnoea $\geqslant 10$ or 20 seconds' duration from the respiration channel and heart rate, or rhythm changes outside preset values from the ECG channel (Oxford Medical Systems). The highest and lowest heart rates were found and then documented on standard ECG paper at $25 \mathrm{~mm} / \mathrm{second}$; the former were measured over 9 beats and the latter over 3,5, and 9 beats' duration. The rhythm over a minimum of 3 successive beats at the lowest heart rates was also noted.

The analyser was set to trigger for all episodes of apnoea $\geqslant 10$ seconds and when these occurred a 40-second memory display of respiration was produced on the oscilloscope. A simultaneous 40second memory of the ECG was also stored for display on a twin oscilloscope. Both ECG and respiration memory stores could be independently printed at $25 \mathrm{~mm} / \mathrm{second}$ on to standard ECG paper. However, to obtain simultaneous printouts (see Figures) of both ECG and respiration, a twin channel fibreoptic recording system was used (Medilec). Only clearly recognisable episodes of apnoea were documented; any episodes of apparently shallow respiration were noted but not analysed in this study.

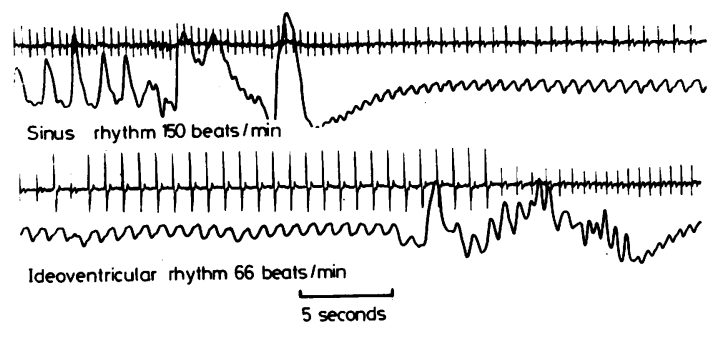

Fig. 3 24-hour ECG and respiration reading from an infant who presented at 5 weeks with an episode of 'near miss' SIDS. The trace begins with sinus rhythm at 150/min and a normal respiratory pattern. 15 seconds after the onset of this record there is an apnoeic episode lasting 40 seconds. Four seconds after the onset of apnoea there is a junctional escape rhythm which gradually becomes slower, until 23 seconds after the onset of the episode an idioventricular rhythm of 66/min occurs. This last escape rhythm persists until the onset of normal respiration. With the fall in heart rate the cardiac impression on the respiration trace becomes arger in amplitude.

Interference from the cardiac impulse often simulated respiration during episodes of apnoea, particularly when associated bradycardia was present. ${ }^{12}$ As the heart rate slowed the stroke volume of the heart increased and in some cases the cardiac signal received on the respiration channel became indistinguishable from normal respiration (Fig. 3). The simultaneous recording of ECG ensured that cardiac impulse interference was recognised by matching the rates. Finally, whenever an apnoeic episode was detected, the presence of associated bradycardia $<100 / \mathrm{min}$ was noted, and the delay between the onset of apnoea and that of the bradycardia was documented.

\section{Results}

Term infant control population $(\mathbf{n}=\mathbf{5 0})$. The distribution of slowest and fastest heart rates (Table 1) was shown to conform to normal by the Kolomogorov-Smirnov test. ${ }^{13}$ At their slowest rates 36 $(72 \%)$ had sinus and $14(28 \%)$ had junctional

Table 1 Heart rate values in controls and preterm, low birthweight infants

\begin{tabular}{|c|c|c|c|c|c|c|c|c|c|c|c|c|c|c|c|c|}
\hline & \multirow{2}{*}{\multicolumn{4}{|c|}{$\begin{array}{l}\text { Highest rate/minute } \\
\text { Measured over } 9 \text { beats }\end{array}$}} & \multicolumn{12}{|c|}{ Lowest rate/minute } \\
\hline & & & & & \multicolumn{4}{|c|}{ Measured over 3 beats } & \multicolumn{4}{|c|}{ Measured over 5 beats } & \multicolumn{4}{|c|}{ Measured over 9 beats } \\
\hline & Min & $\operatorname{Max}$ & Mean & $S D$ & Min & $\operatorname{Max}$ & Mean & $S D$ & Min & $\operatorname{Max}$ & Mean & $S D$ & Min & $\operatorname{Max}$ & Mean & $S D$ \\
\hline \multirow{2}{*}{$\begin{array}{l}\text { Term }(n=50) \\
\text { Preterm } \\
\quad(n=100)\end{array}$} & 150 & 230 & 189 & 20 & 46 & 120 & 79 & 14 & 52 & 120 & 82 & 13 & 61 & 120 & 88 & 13 \\
\hline & 160 & 240 & 195 & 16 & 27 & 140 & 79 & 18 & 35 & 140 & 84 & 18 & 36 & 140 & 91 & 18 \\
\hline
\end{tabular}


escape rhythms (Table 2). Five infants had supraventricular premature beats $>12$ /hour in one (38/ hour); 2 had ventricular premature beats $>12$ /hour in one $(485 /$ hour) (Table 2$)$.

$34(68 \%)$ control infants had apnoeic episodes of 10-14 seconds' duration (Fig. 4) and included 4 $(8 \%)$ with apnoea of $15-19$ seconds' duration and 2 $(4 \%)$ with apnoea $\geqslant 20$ seconds ( 20 and 28 seconds') duration (Table 3).

The average maximum duration of apnoeic episodes $\geqslant 10$ seconds in the 34 members of this group with apnoea $\geqslant 10$ seconds was 13 seconds (95th centile 18 seconds, maximum 28 seconds), Details of the 2 babies with the most prolonged episodes of apnoea are given in Table 4.

50 of a total of 288 episodes of 10-14 seconds, all of 4 episodes of 15-19 seconds, and both of $2>20$ seconds' duration were associated with episodes of bradycardia $<100 \mathrm{~min}$ (Table 3 ). Of a total of 17

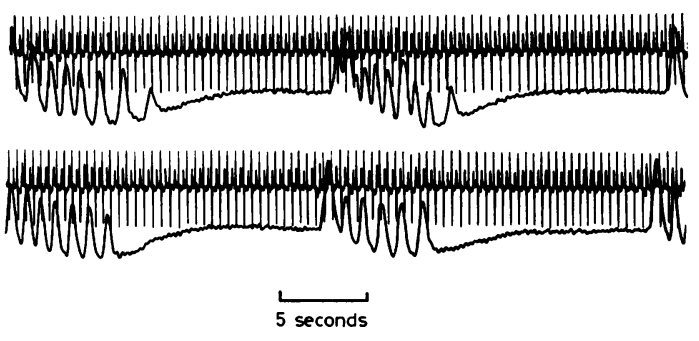

Fig. 4 24-hour ECG and respiration reading showing recurrent episodes of apnoea of between 9 and 13 seconds. ECG shows sinus rhythm of $132 / \mathrm{min}$.

subjects with apnoeic episodes and associated bradycardia of $<100 / \mathrm{min}$ the bradycardia in 2 episodes, in different subjects, started simultaneously with the onset of apnoea and in the remainder after a delay

Table 2 Rhythm at lowest heart rate and frequency of premature beats in term and preterm, low birthweight infants

\begin{tabular}{llllll}
\hline Babies & \multicolumn{1}{l}{ Rhythm at lowest heart rates } & & Premature beats \\
\cline { 2 - 5 } & Sinus & Junctional & Idioventricular & $\begin{array}{l}\text { Junctional }+ \\
\text { idioventricular }\end{array}$ & $\begin{array}{c}\text { Supraventricular } \\
(\text { number/hour })\end{array}$ \\
\hline $\begin{array}{l}\text { Term }(n=50) \\
\begin{array}{l}\text { Preterm } \\
(n=100)\end{array}\end{array}$ & $36(72 \%)$ & $14(28 \%)$ & 0 & 0 & $\begin{array}{c}\text { Ventricular } \\
(\text { (number/hour) }\end{array}$ \\
\hline
\end{tabular}

*One episode (10 beats in duration) of ventricular tachycardia $220 / \mathrm{min}$.

Table 3 24-hour ECG and respiration recordings on term and preterm, low birthweight infants

\begin{tabular}{|c|c|c|c|c|c|c|c|c|c|c|}
\hline \multirow[t]{2}{*}{ Babies } & \multicolumn{4}{|c|}{ Apnoea 10-14 seconds } & \multicolumn{3}{|c|}{ Apnoea 15-19 seconds } & \multicolumn{3}{|c|}{ Apnoea $>20$ seconds } \\
\hline & $\begin{array}{l}\text { No. of } \\
\text { subjects }\end{array}$ & $\begin{array}{l}\text { No. of } \\
\text { episodes } \\
\text { (min-max } \\
\text { no./subject) }\end{array}$ & $\begin{array}{l}\text { No. of } \\
\text { episodes } \\
\text { with } \\
\text { bradycardia } \\
<100 / \text { min }\end{array}$ & $\begin{array}{l}\text { Mean no. } \\
\text { per subject } \\
\text { (95th centile) }\end{array}$ & $\begin{array}{l}\text { No. of } \\
\text { subjects } \\
\text { ) }\end{array}$ & $\begin{array}{l}\text { No. of } \\
\text { episodes } \\
\text { (min-max } \\
\text { no./subject) }\end{array}$ & $\begin{array}{l}\text { No. of } \\
\text { episodes } \\
\text { with } \\
\text { bradycardia } \\
<100 / \text { min }\end{array}$ & $\begin{array}{l}\text { No. of } \\
\text { subjects }\end{array}$ & $\begin{array}{l}\text { No. of } \\
\text { episodes } \\
\text { (min-max } \\
\text { no./subject) }\end{array}$ & $\begin{array}{l}\text { No. of } \\
\text { episodes } \\
\text { with } \\
\text { bradycardia } \\
<100 / \text { min }\end{array}$ \\
\hline $\begin{array}{l}\text { Term } \\
\qquad(n=50)\end{array}$ & $\begin{array}{l}34 \\
(68 \%)\end{array}$ & $\begin{array}{l}288 \\
(1-43)\end{array}$ & 50 & $6(17)$ & $\begin{array}{l}5 \\
(10 \%)\end{array}$ & $\begin{array}{l}4 \\
(1-1)\end{array}$ & 4 & $\begin{array}{l}2^{*} \\
(4 \%)\end{array}$ & $\begin{array}{l}2 \\
(1-1)\end{array}$ & 2 \\
\hline $\begin{array}{l}\text { Preterm } \\
\quad(n=100)\end{array}$ & $\begin{array}{l}65 \\
(65 \%)\end{array}$ & $\begin{array}{l}608 \\
(1-106)\end{array}$ & 84 & $6(12)$ & $\begin{array}{l}21 \\
(21 \%)\end{array}$ & $\begin{array}{l}37 \\
(1-6)\end{array}$ & 21 & $\begin{array}{l}8 \dagger \\
(8 \%)\end{array}$ & $\begin{array}{l}15 \\
(1-7)\end{array}$ & 15 \\
\hline
\end{tabular}

* Maximum duration 28 seconds, tmaximum duration 52 seconds (Figs 8 and 9).

Table 4 Details on the 7 infants with the most prolonged apnoeic episodes (>95th centile)

\begin{tabular}{|c|c|c|c|c|c|c|c|}
\hline Case & $\operatorname{Sex}$ & $\begin{array}{l}\text { Birthweight } \\
\text { (g) }\end{array}$ & $\begin{array}{l}\text { Gestation } \\
\text { (weeks) }\end{array}$ & $\begin{array}{l}\text { Age } \\
\text { (days) }\end{array}$ & $\begin{array}{l}\text { Rhythm at lowest } \\
\text { heart rate }\end{array}$ & $\begin{array}{l}\text { Minimum heart rate } \\
\text { measured over } 9 \text { beats }\end{array}$ & $\begin{array}{l}\text { Duration of maximum } \\
\text { apnoeic episode (seconds) }\end{array}$ \\
\hline \multicolumn{8}{|l|}{ Term } \\
\hline 1 & $\mathbf{F}$ & $>2500$ & 40 & 2 & Sinus & 71 & 28 \\
\hline 2 & $\mathbf{F}$ & $>2500$ & 41 & 7 & Sinus & 95 & 20 \\
\hline \multicolumn{8}{|c|}{ Preterm } \\
\hline 3 & $\mathbf{M}$ & 1190 & 30 & 64 & Junctional & $36^{*}$ & 52 (Figs 8 and 9) \\
\hline 4 & $\mathbf{M}$ & 2520 & 34 & 17 & Sinus & 92 & 22 \\
\hline $5 \dagger$ & $\mathbf{M}$ & 2110 & 33 & 19 & $\begin{array}{l}\text { Junctional }+ \\
\text { idioventricular }\end{array}$ & 70 & 21 \\
\hline 6 & $\mathbf{F}$ & 2090 & 33 & 34 & Junctional & 68 & 20 \\
\hline 7 & $\mathbf{F}$ & 1560 & 32 & 38 & Junctional & 61 & 20 \\
\hline
\end{tabular}

*Including $3 \cdot 2$ seconds of asystole, talso had 109 ventricular premature beats/hour. 
of between 2 and 13 seconds (average 5 seconds). In one baby bradycardia started 3 seconds before an apnoeic episode. In this population numerous episodes of bradycardia $<100 /$ min occurred in the absence of associated apnoea (as measured by the impedance technique). Finally, in 4 babies the apnoea continued after the bradycardia had ended (Fig. 5).
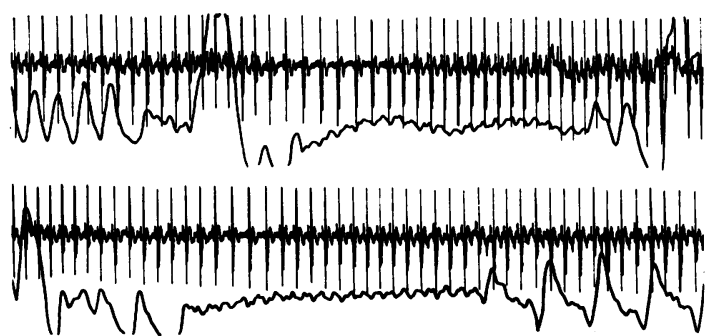

$$
\underset{5 \text { seconds }}{\longrightarrow}
$$

Fig. 5 24-hour ECG and respiration recording shows two episodes of apnoea, the first episode of 15 seconds, the second of 17 seconds. A bradycardia of $72 / \mathrm{min}$, containing a junctional escape rhythm, begins at the onset of the first apnoeic episode, but the apnoea continues for a further 10 seconds after the end of this bradycardia. A similar sequence of events occurs with the second apnoeic episode.

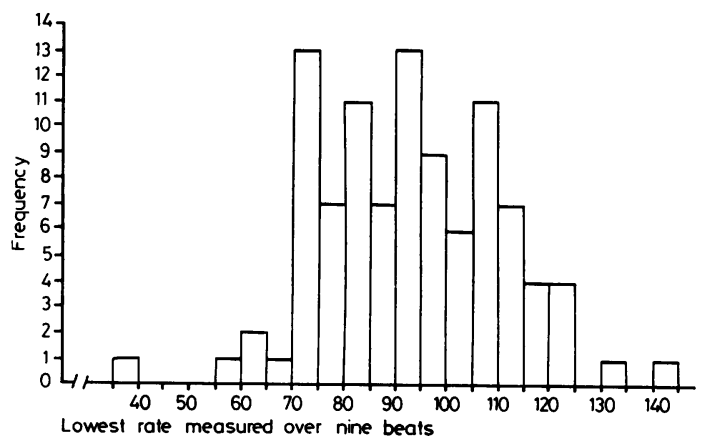

Fig. 6 Histogram from direct ECG analysis of the minimum heart rates measured over 9 consecutive beats in 100 healthy low birthweight infants studied immediately before their discharge home (this histogram follows a normal distribution).
Low birthweight and preterm population $(n=100)$. The distribution of lowest and highest heart rates was also shown to conform to normal by the Kolomogorov-Smirnov test (Fig. 6, Table 1). ${ }^{13}$ At their lowest heart rates 78 were in sinus rhythm, 18 had junctional, one idioventricular (Fig. 7), and 3 had both idioventricular and junctional escape rhythms (Table 2).

Two had supraventricular and 6 had ventricular premature beats (Table 2). Of the 2 with supraventricular premature beats, none had $>12$ /hour, but 3 of the 6 infants with ventricular premature beats had $>12 /$ hour $(19,109$, and 258 /hour). A further subject had a single episode of 10 beats' duration of ventricular tachycardia $(220 / \mathrm{min})$ (Table 2).

66 babies in this group had apnoeic episodes $\geqslant 10$ seconds' duration, 65 had apnoea of 10-14 seconds, including 21 with apnoea of 15-19 seconds' duration and 8 with apnoea $\geqslant 20$ seconds (Table 3). One baby had apnoea of 15-19 seconds without episodes of apnoea of 10-14 seconds.

The average maximum duration of apnoeic episodes in the 66 infants with apnoea $\geqslant 10$ seconds was 14 seconds (95th centile 20 seconds, maximum 52 seconds (Figs 8 and 9)).

Details of the 5 babies with the most prolonged apnoeic episodes are shown in Table 4.

34 babies had apnoeic episodes of $\geqslant 10$ seconds, associated with bradycardia. In 3 the bradycardia started simultaneously with the onset of apnoea and in the remainder after a delay of between 3 and 20 seconds (average 8 seconds) (Fig. 10).

Numerous episodes of bradycardia without associated apnoea, as documented by impedance changes, occurred in this group.

The frequency of apnoeic episodes of 10-14 seconds' duration correlated with gestation at birth: the more preterm the more frequent the apnoeic episodes on discharge from hospital (Spearman rank correlation $P<0 \cdot 05$ ). Apnoea $>14$ seconds did not correlate significantly. Apnoeic episodes $<20$ seconds were also present more frequently in the preterm, than in the preterm plus small-for-dates groups, or in the small-for-dates group alone $(P<0.02$ for $10-14$ seconds, $P<0.05$ for $15-19$ seconds; Mann-Whitney U test. ${ }^{13}$ Apnoeic episodes $>20$ seconds were not significantly correlated with maturity category.

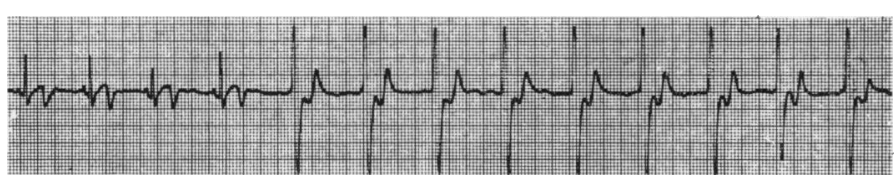

Fig. 7 24-hour ECG and respiration recording shows ECG at $25 \mathrm{~mm} / \mathrm{second}$. There is an episode of idioventricular rhythm at 73/min. The wide and bizarre QRS-complex indicates a ventricular origin for this escape rhythm. 
Near-miss SIDS and sibling SIDS group $(n=6)$. Details of recordings on 5 babies with near-miss SIDS and one infant with 2 previous siblings with SIDS are shown in Table 5 (Figs 11 and 3). Four

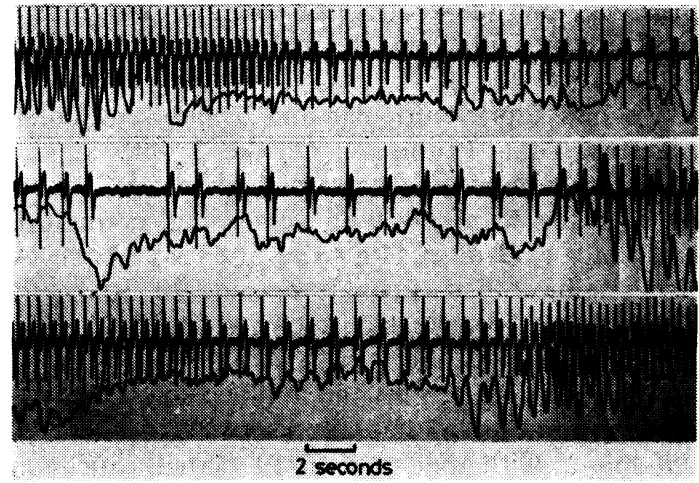

Fig. 8 24-hour ECG and respiration recording from an apparently healthy preterm infant studied at age 64 days, 2 days before discharge home. Six seconds after the onset of the recording there is a 'sigh' followed by an episode of apnoea of 52 seconds. Five seconds after the onset of apnoea there is sudden sinus bradycardia which persists until 5 seconds after the end of this apnoeic episode. A junctional escape rhythm associated with cardiac asystole of $3 \cdot 3$ seconds takes over after 18 seconds of this bradycardia. There is a shorter episode of apnoea and bradycardia in the lowest panel. Six other episodes of apnoea $>20$ seconds' duration occurred during this 24-hour recording.

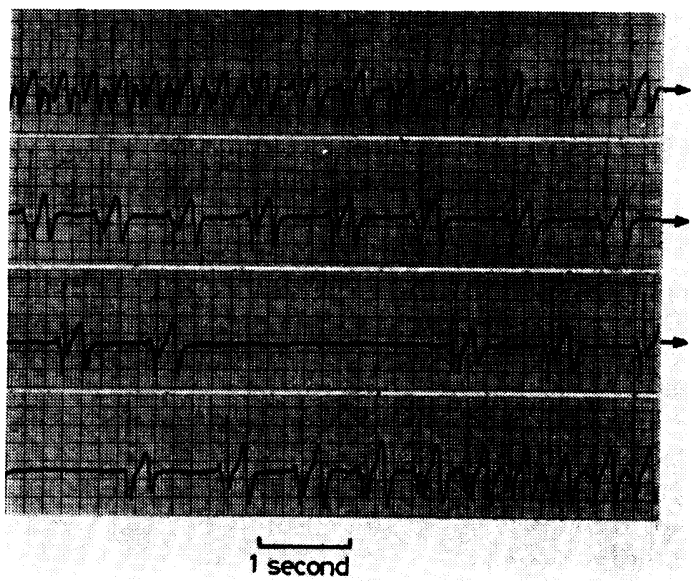

Fig. 9 Section of 24-hour ECG recording at $25 \mathrm{~mm} /$ second illustrating the ECG features of the episode of apnoea and bradycardia shown in Fig. 8. Top panel shows the development of sinus bradycardia. During the second panel the PR-interval is much shorter due to a junctional escape rhythm. In the third panel there is a sinus pause of 3.3 seconds. out of 6 in this group, when studied on 24-hour recordings, had prolonged apnoea ( $>40$ seconds) or extreme bradycardia $(<50 / \mathrm{min})$ or both.

Infants with arrhythmias on a standard ECG $(n=11)$. Recordings on infants with premature beats or episodes of supraventricular tachycardia are shown in Table 6 (Fig. 12). All infants with premature beats, and 3 of 5 with episodes of bradycardia, failed to show apnoea during arrhythmias. Two babies with episodes of bradycardia had associated apnoea of 10-14 seconds' duration.

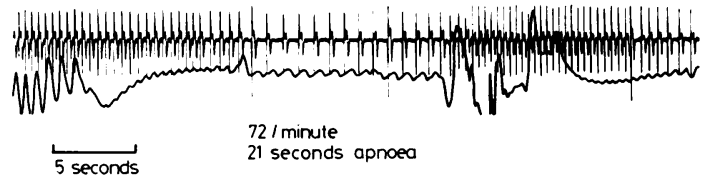

Fig. 10 24-hour ECG and respiration recording showing an apnoeic episode of 21 seconds. A sinus bradycardia leading to a junctional escape rhythm of $72 /$ min begins 8 seconds after onset of apnoea. In addition there are two larger complexes during the apnoea which represent idioventricular escape beats. These beats are large, the $Q R S$ is widened, and their configuration is similar to ventricular premature beats, one of which occurs 5 seconds from the end of this illustration.
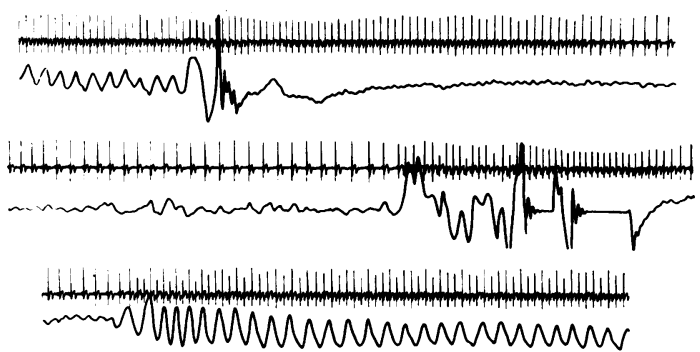

5 seconds

Fig. 11 24-hour ECG and respiration recording on an apparently healthy preterm infant of 32 weeks' gestation, weight $1.47 \mathrm{~kg}$ at birth. At age 53 days he collapsed and needed artificial ventilation and external cardiac massage before recovering (an example of a 'near-miss' SIDS). This recording was performed 4 days later. 11 seconds after the beginning of the illustration there is a large signal on the respiration carrier followed by apnoea of 45 seconds. 20 seconds after the onset of this apnoea there is a sinus bradycardia leading to a junctional escape rhythm. This episode of bradycardia ends with the termination of apnoea. After this attack there is an episode of hyperventilation (producing a characteristic pattern on the respiration channel (see Fig. 2)). 
Table 5 Details of combined 24-hour record of ECG and respiration on 5 'near-miss' cot death infants and one preterm infant with 2 siblings with SIDS

\begin{tabular}{|c|c|c|c|c|c|}
\hline $\begin{array}{l}\text { Birthweight } \\
(\mathrm{kg})\end{array}$ & $\begin{array}{l}\text { Gestation } \\
\text { (weeks) }\end{array}$ & $\begin{array}{l}\text { Age } \\
\text { (days) }\end{array}$ & $\begin{array}{l}\text { 24-hour ECG lowest } \\
\text { heart rates (over } 3 \\
\text { beats) }\end{array}$ & $\begin{array}{l}\text { 24-hour respiration } \\
\text { maximum duration of } \\
\text { apnoea (seconds) }\end{array}$ & Clinical features \\
\hline $\begin{array}{l}1 \cdot 47 \\
2 \cdot 20 \\
2 \cdot 36 \\
3 \cdot 92 \\
3 \cdot 75 \\
1 \cdot 50\end{array}$ & $\begin{array}{l}32 \\
34 \\
37 \\
40 \\
40 \\
30\end{array}$ & $\begin{array}{l}57 \\
35 \\
38 \\
79 \\
77 \\
78\end{array}$ & $\begin{array}{l}56 \\
41 \\
55^{*}(\text { Fig 3) } \\
66 \\
42 \\
39^{*}\end{array}$ & $\begin{array}{l}45 \dagger \text { (Fig 11) } \\
75 \dagger \\
60 \dagger \\
14 \dagger \\
<10 \\
14 \dagger\end{array}$ & $\begin{array}{l}\text { Near miss SIDS } \\
\text { Near miss SIDS } \\
\text { Near miss SIDS } \\
\text { Near miss SIDS } \\
\text { Near miss SIDS } \\
\text { Preterm with } 2 \text { siblings SIDS }\end{array}$ \\
\hline
\end{tabular}

*Idioventricular rhythm at lowest heart rate, tassociated bradycardia $<100 / \mathrm{min}$.

Table 6 Combined 24-hour ECG and respiration recordings on infants with arrhythmias on the standard ECG

\begin{tabular}{|c|c|c|c|c|}
\hline \multirow[t]{2}{*}{ Cases } & \multirow[t]{2}{*}{ Standard ECG } & \multicolumn{2}{|l|}{ 24-hour recording } & \multirow[t]{2}{*}{ Clinical features } \\
\hline & & $E C G$ & Respiration & \\
\hline $8-10$ & APBs & $\begin{array}{l}195 \mathrm{APBs} / \mathrm{h}, 8 \mathrm{APBs} / \mathrm{h}, \\
1100 \mathrm{ABPS} / \mathrm{h} \text { (Fig. 13) }\end{array}$ & No apnoea $\geqslant 10 \mathrm{~s}$ & \\
\hline 11 & APBs & $\begin{array}{l}\text { Numerous APBs with } \\
\text { supraventricular } \\
\text { tachycardia } 260 / \mathrm{min}\end{array}$ & No apnoea $\geqslant 10 \mathrm{~s}$ & Irregular fetal heart \\
\hline $\begin{array}{l}12 \\
13\end{array}$ & $\begin{array}{l}\text { VPBs } \\
\text { VPBs }\end{array}$ & $\begin{array}{l}1100 \mathrm{VPBs} / \mathrm{h} \\
2 \text { episodes of ventricular } \\
\text { tachycardia } 180 / \mathrm{min}\end{array}$ & $\begin{array}{l}\text { No apnoea } \geqslant 10 \mathrm{~s} \\
\text { No apnoea } \geqslant 10 \mathrm{~s}\end{array}$ & Irregular fetal heart \\
\hline 14,15 & $\begin{array}{l}\text { Sudden slowing of rate to } \\
60 / \mathrm{min}\end{array}$ & $\begin{array}{l}\text { Episodes of bradycardia to } \\
56 / \mathrm{min}\end{array}$ & Associated apnoea $10-14 \mathrm{~s}$ & $\begin{array}{l}\text { Cyanotic attacks in one } \\
\text { subject }\end{array}$ \\
\hline $16-17$ & $\begin{array}{l}\text { Sudden slowing of rate to } \\
65 / \mathrm{min}\end{array}$ & $\begin{array}{l}\text { Frequent episodes of } \\
\text { bradycardia to } 65 / \mathrm{min}\end{array}$ & No apnoea $\geqslant 10 \mathrm{~s}$ & \\
\hline 18 & $\begin{array}{l}\text { Sudden slowing of rate to } \\
68 / \mathrm{min}\end{array}$ & $\begin{array}{l}\text { Frequent episodes of } \\
\text { bradycardia to } 55 / \mathrm{min} \\
\text { Supraventricular tachycardia } \\
240 / \mathrm{min}\end{array}$ & No apnoea $\geqslant 10 \mathrm{~s}$ & Slow fetal heart rate \\
\hline
\end{tabular}

$\mathbf{A P B}=$ Atrial premature beat, $\mathrm{VPB}=$ ventricular premature beat.

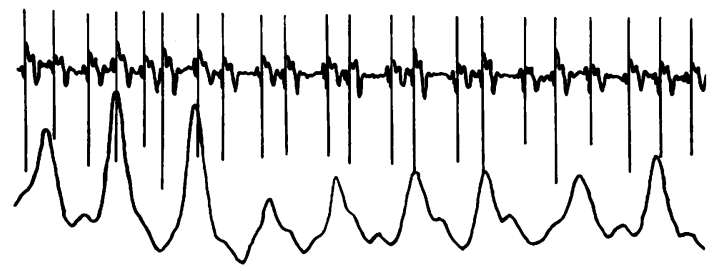

Fig. 12 24-hour ECG and respiration recording showing multiple supraventricular premature beats and a normal pattern of respiration during the arrhythmia.

Finally, Fig. 13 gives details of maximum apnoeic duration attained over 24 hours correlated with minimum heart rate attained over 24 hours for individual preterm, term, and near-miss cot death subjects.

\section{Discussion}

Value of combined 24-hour ECG and respiration recordings. 24-hour tape recording and analysis provides an efficient means of simultaneously

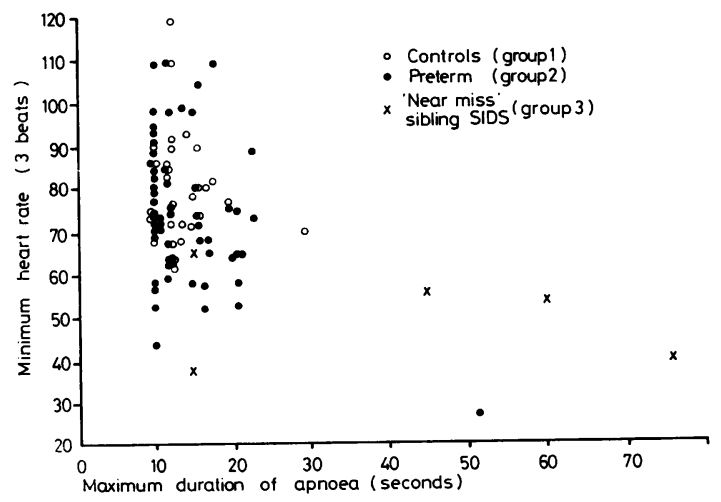

Fig. 13 Minimum heart rate (measured over 3 beats) and the maximum duration of apnoea attained over the 24-hour period are plotted for each subject (controls, preterm on discharge from hospital, and near-miss SIDS). This graph shows that most subjects have minimum lowest heart rates of $>50 / \mathrm{min}$ and maximum apnoea duration of $<25$ seconds. One preterm and 3 near-miss subjects are positioned widely outside these normal values. 


\section{Southall, Richards, Brown, Johnston, de Swiet, and Shinebourne}

investigating heart rate and rhythm changes from the ECG and respiration pattern from impedance pneumography. The technique is noninvasive, safely performed in hospital or at home, and each recording can be analysed in 30 to 45 minutes. The often intermittent nature of episodes of apnoea and bradycardia necessitates a long-term recording system for their documentation. Stein and Shannon ${ }^{14}$ showed the value of tape recordings of respiration alone in the care of ill preterm infants. However, impedance pneumography does not detect upper airway obstructive apnoea, changes in chest wall dimensions continuing in the absence of air entry. ${ }^{8}$ Such episodes, particularly when prolonged enough to produce hypoxaemia, are generally associated with bradycardia, and simultaneous documentation of the ECG on our tape recording system helps to prevent clinically relevant episodes from remaining undetected. Similarly, as mentioned earlier, by matching the ECG signal to that of respiration, cardiac impulse interference during apnoea may be avoided (Fig. 3).

Respiration patterns and heart rhythm in infancy. The frequency and duration of apnoeic episodes found in this study differ from those described in other studies of respiration in healthy term infants, possibly because of our longer recording time and larger population. For example, the percentage of babies $(68 \%)$ with episodes of apnoea $>9$ seconds is much greater than in other studies of term infants $-13 \%{ }^{15}$ and $9-22 \%{ }^{16}$ Only one other study has reported apnoea exceeding 20 seconds in duration. ${ }^{17}$

Previously reported studies of long-term ECG recordings on preterm infants ${ }^{18-20}$ cannot be compared with the recordings made in our study. All previous measurements were made in the first days of life and some of the infants were unwell, unlike our population of healthy preterm infants screened immediately before their discharge home.

Both supraventricular and ventricular premature beats were common findings in term and preterm infants on discharge from hospital. Four preterm infants and 2 near-miss 'cot death' babies showed episodes of idioventricular rhythm, associated in 5 of them with episodes of apnoea. This escape rhythm has not previously been described in infancy.

Relationship between heart rate, heart rhythm, and apnoea in infancy. The relationship between apnoea and bradycardia found in this study agrees with previous reports. ${ }^{41-22}$ During most episodes, bradycardia follows the onset of apnoea by a shorter period of time than would be expected if hypoxaemia were the cause (Fig. 8). In others, particularly in those with near-miss SIDS, there is a longer period of apnoea before bradycardia, suggesting that hypoxaemia may be responsible (Fig. 11). It is possible that in some cases apnoea is preceded by upper airways obstruction (undetected by impedance pneumography), in which case the duration of apnoeic episodes, that is cessation of air entry, may be even greater than we have described. Also, some episodes of bradycardia, seemingly without associated apnoea on the tracing, may be associated with upper airways obstruction.

It is likely that most episodes of bradycardia, with or without apnoea, are automatic reflex events related for example to defecation, hiccoughing, or vomiting rather than to hypoxaemia. ${ }^{23}$ This hypothesis is supported, in some cases by a continuation of apnoea after the bradycardia has ended (Fig. 5).

24-hour ECG and respiration recordings on infants with arrhythmias on a standard ECG showed that premature beats or supraventricular tachycardias were not associated with apnoea, implying that they are primary disorders of cardiac conduction. Some infants with episodes of bradycardia had associated apnoea and some did not. The former may represent autonomic reflex events and the latter primary change in cardiac conduction.

Findings related to sudden infant death and hypoxaemic brain damage. Between 60 and $75 \%$ of preterm infants during the first days or weeks of life have prolonged apnoea $>20$ seconds. ${ }^{4-6}$ These episodes often occur during sleep. ${ }^{24-25}$ Many lead to hypoxaemia, require resuscitation, and are life threatening. Our hypothesis that some preterm infants on discharge from hospital may have dangerous prolonged apnoea not detected by clinical observation was supported by the finding in one such infant of apnoea $>50$ seconds. This infant had been at home for 4 days before the tape recording was analysed but no abnormal features had been noticed, either by nursing staff before discharge from hospital, or by his parents.

The true incidence of prolonged apnoea in the apparently healthy preterm infant on discharge from hospital requires the study of a much larger population. This finding of a higher frequency of hidden prolonged apnoea in the preterm group than in the term group may explain the higher incidence of SIDS in preterm than in term infants (6-12/1000 preterm, ${ }^{9-11}$ 2/1000 term, J R Oakıey, 1978, personal communication).

Finally, Steinschneider, ${ }^{726}$ and Guilleminault, ${ }^{8}$ showed that the frequency and duration of prolonged apnoea is enhanced by the presence of respiratory infection. Up to $40 \%$ of infants who 
suffer SIDS have been reported to have had preceding minor respiratory infections. ${ }^{9}$ It is therefore also possible that infants with prolonged apnoea represent a high risk group who, with intercurrent illness, die suddenly and unexpectedly.

The incidence of some form of brain damage in the survivors of preterm, low birthweight babies has been reported to be between $<3$ and $33 \%,{ }^{27}$ a much higher frequency than in the term infant. Much of this damage occurs because of antenatal or immediate postnatal problems, but is it possible that in a proportion of preterm infants, hypoxaemia related to late onset, hidden, prolonged apnoea may be responsible?

Assuming a resting lung volume of $30 \mathrm{ml} / \mathrm{kg}$ and $\mathrm{O}_{2}$ consumption of $7 \mathrm{ml} / \mathrm{kg}$ per min (representative for the neonate) alveolar $\mathrm{Po}_{2}$ will have fallen from 100 to $25 \mathrm{mmHg}(13 \cdot 3$ to $3 \cdot 3 \mathrm{kPa})$ and the blood in the pulmonary veins will only be $50 \%$ saturated after 36 seconds of apnoea in a 3-kg infant (E Hey, 1979, personal communication). Pronounced hypoxaemia was therefore present in our preterm infant with apnoea $>50$ seconds.

All previously reported work on prolonged apnoea and SIDS has resulted from the study of near-miss cot death patients. ${ }^{7-8} 28$ These findings, and our own, show that many patients, particularly those of low birthweights, have prolonged apnoea and bradycardia. However in the study of near-miss patients it is possible that hypoxaemic brain damage associated with the original episode could result in the subsequent attacks of apnoea and bradycardia. ${ }^{29}$ Brain damage both in infants ${ }^{30}$ and adults ${ }^{31}$ has been shown to predispose to such episodes.

Fig. 13 shows that it may now be possible to recognise a baby with an abnormal 24-hour ECG and respiration recording. If our hypothesis that infants with abnormal apnoea or bradycardia are at excessive risk of SIDS or postnatal brain damage is true, then infants at high risk may be identified and given preventive treatment.

\section{Conclusion}

This study has defined a range of normal values for ECG and respiration patterns in newborn infants before their discharge home. One of 100 apparently healthy low birthweight infants showed prolonged apnoea and extreme bradycardia. Similar findings were demonstrated in recordings of 'near-miss' SIDS subjects, and in a baby whose 2 siblings had died from SIDS. Sudden death and brain damage both occur more frequently in preterm infants and a possible relationship between these events and prolonged apnoea and bradycardia will only be determined by a prospective study that demonstrates an excess of sudden death or brain damage in a population of healthy preterm infants identified as having these disorders on discharge from hospital.

\section{Addendum}

In a subsequent and continuing study of 140 preterm or low birthweight infants, 3 had episodes of bradycardia $<50$ /minute including 2 with apnoea exceeding 30 seconds (31s, 37s). Thus in total prolonged apnoea (exceeding 30 seconds) and/or extreme bradycardia ( $<50 /$ minute) was detected in 4 of 240 preterm or low birthweight infants.

We thank Professor E O R Reynolds, Dr R Dinwiddie, Dr T French, Dr H R Gamsu, Dr D R Harvey, Dr H C Issler, Dr R A K Jones, Dr R Orme, Dr P G F Swift, Dr S M Tucker, Dr R G Wilson, Mrs J Quigley, and Mrs M Callam for their help, and Elaine Southall and Dorothy Lewis for secretarial assistance.

D P S is supported by a grant from the Board of Governors of the Brompton Hospital, National Heart and Chest Hospitals, and J R by a grant from the Foundation for the Study of Sudden Infant Death. The 24-hour ECG and respiration recorder was developed with the aid of a grant from the Wessex Regional Health Authority and with assistance from the Oxford Instrument Company and the Electronics Department of the Brompton Hospital. The analyser was supplied by the British Heart Foundation.

\section{References}

1 Southall D P, Vulliamy D G, Davies M J, Anderson R H, Shinebourne E A, Johnson A M. A new look at the neonatal electrocardiogram. Br Med J 1976; 2: 615-18.

2 Southall D P, Orrell M J, Talbot J F, et al. Study of cardiac arrhythmias and other forms of conduction abnormality in newborn infants. Br Med J 1977; 2 : 597-9.

3 Southall D P, Richards J M, Johnston P G B, Shinebourne E A. Study of cardiac rhythm in healthy newborn infants (abstract). Br Heart J 1979; 41 : 382.

4 Daily W J R, Klaus M, Meyer H B P. Apnea in premature infants: monitoring, incidence, heart rate changes, and an effect of environmental temperature. Pediatrics 1969; 43: 510-18.

5 Krauss A N, Solomon G E, Auld P A M. Sleep state, apnoea, and bradycardia in preterm infants. Dev Med Child Neurol 1977; 19: 160-8.

6 Miller H C, Behrle F C, Smull N W. Severe apnea and irregular respiratory rhythm among premature infants. Pediatrics 1959; 23: 676-85.

7 Steinschneider A. Prolonged apnea and the sudden infant death syndrome: clinical and laboratory observations. Pediatrics 1972: 50: 646-54.

8 Guilleminault C, Peraita R, Souquet M, Dement W C. Apneas during sleep in infants; possible relationship with sudden infant death syndrome. Science 1975; 190: 677-9. 
9 Bergman A B, Ray G, Pomeroy M A, Wahl P, Beckwith $J$ B. Studies of the sudden infant death syndrome in King County, Washington. III. Epidemiology. Pediatrics 1972; 49: 860-70.

10 Steele R, Krauss A N, Langworth J T. Sudden unexpected death in infancy in Ontario. Can J Public Health 1967; 58: $359-71$.

11 Stewart A L, Turcan D, Rawlings G, Hart S, Gregory S. Outcome for infants at high risk of handicap. In: Elliott K M, O'Connor M, eds. Major mental handicap methods and costs of prevention. Ciba Symposium No. 59. Amsterdam: Elsevier-Excerpta Medica-North-Holland, 1978: 151-64.

12 Southall D P, Richards J M, Lau K C, Shinebourne E A. An explanation for failure of impedance apnoea alarm systems. Arch Dis Child 1980; 55: 63-5.

13 Siegel S. Non parametric statistics. New York: McGraw Hill, 1956; 36-40.

14 Stein L M, Shannon D C. The pediatric pneumogram: a new method for detecting and quantitating apnea in infants. Pediatrics 1975; 55: 599-603.

15 Franks C I, Johnston D M, Brown B H. Non-invasive home monitoring of respiratory patterns in infants. Dev Med Child Neurol 1977; 19: 748-56.

16 Thoman E B, Miano V N, Freese M P. The role of respiratory instability in the sudden infant death syndrome. Dev Med Child Neurol 1977; 19: 729-38.

17 Hoppenbrouwers T, Hodgman J E, Harper $\mathbf{R}$, Hofmann M B, Sterman M B, McGinty D J. Polygraphic studies of normal infants during the first six months of life. III. Incidence of apnea and periodic breathing. Pediatrics 1977; 60: 418-25.

18 Morgan B C, Bloom R S, Guntheroth W G. Cardiac arrhythmias in premature infants. Pediatrics 1965; 35: 658-61.

19 Church S C, Morgan B C, Oliver T K, Jr, Guntheroth W G, Cardiac arrhythmias in premature infants: an indication of autonomic immaturity? J Pediatr 1967; 71: 542-6.

20 Välimäki I. Tape recordings of the electrocardiogram in newborn infants. Acta Paediatr Scand 1969; Supplement 199.

21 Rigatto H, Brady J P. Periodic breathing and apnea in preterm infants. I. Evidence for hypoventilation possibly due to central respiratory depression. II. Hypoxia as a primary event. Pediatrics 1972; 50: 202-18, 219-28.

22 Storrs C N. Cardiovascular patterns of apnoea in preterm infants. Arch Dis Child 1977; 52: 534-40.

23 Lipton E L, Steinschneider A, Richmond J B. Autonomic function in the neonate. VIII. Cardiopulmonary observations. Pediatrics 1964; 33: 212-15.

24 Gabriel M, Albani M, Schulte F J. Apneic spells and sleep states in preterm infants. Pediatrics 1976; 57: 142-7.

25 Gould J B, Lee A F S, James O, Sander L, Teager H, Fineberg $\mathrm{N}$. The sleep state characteristics of apnea during infancy. Pediatrics 1977; 59: 182-94.

26 Steinschneider A. Nasopharyngitis and prolonged sleep apnea. Pediatrics 1975; 56: 967-71.

27 Davies P A, Stewart A L. Low birth weight infants: neurological sequelae and later intelligence. $\mathrm{Br}$ Med Bull 1975 ; 31; 85-91.

28 Guilleminault C, Ariagno R, Souquet M, Dement W C. Abnormal polygraphic findings in near-miss sudden infant death. Lancet 1976; 1 : 1326-7.

29 Editorial: Cot death and respiratory drive. Lancet 1977; 2: 1064.

30 Theorell K. Clinical value of prolonged polygraphic recordings of high-risk newborn infants. Neuropaediatrie 1974; 5: 383-401.

31 North J B, Jennett S. Impedance pneumography for the detection of abnormal breathing patterns associated with brain damage. Lancet $1972 ; 2$ : 212-3.

Correspondence to $\mathrm{Dr}$ D P Southall, Cardiothoracic Institute, Fulham Road, London SW3 $6 \mathrm{HP}$.

Received 25 May 1979 